\title{
A novel preparation method for drug nanocrystals and characterization by ultrasonic spray-assisted electrostatic adsorption
}

This article was published in the following Dove Press journal:

International Journal of Nanomedicine

10 October 2013

Number of times this article has been viewed

\author{
Bing Gao ${ }^{1-3}$ \\ Jun Wang ${ }^{2}$ \\ Dunju Wang ${ }^{1,2}$ \\ Ziqiang Zhu ${ }^{1,2}$ \\ Zhiqiang Qiao ${ }^{2}$ \\ Guangcheng Yang ${ }^{2}$ \\ Fude $\mathrm{Nie}^{2}$ \\ 'School of Material Science and \\ Engineering, Southwest University \\ of Science and Technology, Mianyang, \\ People's Republic of China, ${ }^{2}$ Institute \\ of Chemical Materials, China Academy \\ of Engineering Physics, Mianyang, \\ Sichuan, People's Republic of China, \\ ${ }^{3} \mathrm{Si}$ Chuan Research Center of New \\ Materials, Mianyang, People's Republic \\ of China
}

Purpose: The purpose of this study was to develop a novel and continuous method for preparing a nanosized particle of drug crystals and to characterize its properties.

Materials and methods: A new apparatus was introduced to crystallize nanosized drug crystals of amitriptyline hydrochloride as a model drug. The samples were prepared in the pure state by ultrasonic spray, and elaborated deposition was completed via electrostatic adsorption. Scanning electron microscopy, X-ray powder diffraction, and atomic force microscopy were used to characterize the size of the particles; this was subsequently followed by differential scanning calorimetry.

Results and discussion: Nanoparticles of drug crystals were successfully prepared. The size of the drug crystals ranged from $20 \mathrm{~nm}$ to $400 \mathrm{~nm}$; the particle size of amitriptyline hydrochloride was approximately $71 \mathrm{~nm}$. The particles were spherical and rectangular in shape. Moreover, the melting point of the nanoparticles decreased from $198.2^{\circ} \mathrm{C}$ to $196.3^{\circ} \mathrm{C}$ when compared to raw particle crystals. Furthermore, the agglomeration effect was also attenuated as a result of electrostatic repulsion among each particle when absorbed, and depositing on the inner wall of the gathering unit occurred under the electrostatic effect.

Conclusion: Ultrasonic spray-assisted electrostatic adsorption is a very effective and continuous method to produce drug nanocrystals. This method can be applied to poorly water-soluble drugs, and it can also be a very effective alternative for industrial production. Once the working parameters are given, drug nanocrystals will be produced continuously.

Keywords: nanomedicine, amitriptyline hydrochloride, continuous, nanoparticles

\section{Introduction}

Nanomedicine is the subfield of nanotechnology that uses nanomaterials for cancer diagnosis, ${ }^{1-3}$ gene transfer, ${ }^{4,5}$ imaging and drug delivery, ${ }^{6-8}$ and so on, by engineering their structures, compositions, sizes, and shapes, and by modifying their surfaces with ligands ${ }^{9}$ at the atomic and molecular scale. Nano drug delivery is one of the most interesting areas in nanomedicine. Nanoparticles are defined with a nanoscale in the range of 10-1,000 nm; they are smaller than cells and can yield pleasantly surprising effects. Nanocapsules, ${ }^{10,11}$ nanobubbles, ${ }^{12}$ nanoliposomes, ${ }^{13,14}$ micelles, ${ }^{15,16}$ and nanoparticles ${ }^{6,17}$ have been explored with some success for developing high-performance delivery systems in the past few years. However, low encapsulation efficiency and relatively good chemical stability are still not satisfactory. The elaboration of nanosized crystals had been introduced by different methods due to its advantages of precise control of size, dosage form diversification, and high level of drug release (approximately $100 \%$ ). Three methods (milling, precipitation methods, and homogenization), as well
Correspondence: Guangcheng Yang Fude Nie

Institute of Chemical Materials, China Academy of Engineering Physics, Mianyang, Sichuan, 621900, People's Republic of China

Tel +868162544436

Fax +868162544426

Email ygcheng@hotmail.com; zgh-nfd@sohu.com 
as a possible combination of these methods, can be used to produce nanocrystals of a desired shape and size.

As the classical nanocrystal technology, milling methods - which are known as top-down approaches to nano materials from the first half of the 20th century - by a stainless steel ball or a pearl mill, are completed by filling with a container to achieve particle size diminution. The drug material to be crushed is added in the form of a powder with a grain size diameter of about 50-100 $\mu \mathrm{m}$, and the milling time can last from about 30 minutes to several hours or several days, depending on the different drugs and many other factors such as the surfactant content, hardness of the drug, viscosity, temperature, energy input, and size of the milling media. ${ }^{18-22}$ This process is simple and low-energy; however, its weaknesses lie in the fact that the grinding balls contribute to impurities, and it is a slow process. Precipitation methods are the other method used to make nanosized drug materials; hydrosol is essentially a classical precipitation process known as "via humida part-time." The drug materials are dissolved in a solvent and are subsequently added to a nonsolvent, leading to the precipitation of finely dispersed drug nanocrystals. ${ }^{23,24}$ Oil/water two-phase system regions are excellent and effective carriers; they are characterized by bioavailability solubility, and improve the bioavailability of only poorly water-soluble drugs. They are not universally applicable for most drug materials. High-pressure homogenization, a simple process that was developed in 1999 for nanoparticle production, is also used for preparing nanosized drugs. ${ }^{25}$ Only drugs that are poorly water soluble in both aqueous and organic media can be easily formulated into nanoparticulate suspensions. The advantage of this process is that it is a fast method and it is a continuous process. This method needs high-energy techniques and requires a great level of experience. In addition, nanoparticle agglomeration, which reduces the specific surface area, still exists and can reduce the effect of nanoparticles to a certain extent.

The objective of this study was to develop a new and continuous method for the atomization process in the preparation of nano- and submicro-sized drug particles for the first time.

An ultrasonic nebulizer is used to generate the aerosol in which a piezoelectric transducer is located at the central part of the bottom of the container. When the piezoelectric transducer is switched on, ultrafine droplets generate on the upper surface of the liquid due to the qualification caused by ultrasonic waves generated in the liquid. The mechanism of ultrasonic atomization, by which vibration of the liquid surfaces causes atomization, has been studied by Lang. ${ }^{26}$
The droplet size can be estimated reasonably accurately using Lang's equation: ${ }^{26}$

$$
\mathrm{d}_{\mathrm{p}}=0.34\left(8 \pi \sigma /\left[\rho \mathrm{f}^{2}\right]\right)^{(1 / 3)}
$$

where $d_{p}$ is the droplet size, $\sigma$ is the surface tension (dyne $/ \mathrm{cm}$ ), $\rho$ is the density $(\mathrm{g} / \mathrm{mL})$, and $\mathrm{f}$ is the excitation frequency $(\mathrm{Hz})$. A constant fraction of 0.34 of certain frequencies ranging from $10-800 \mathrm{kHz}$ is given. The capillary wavelength is calculable by Kelvin's equation using the excitation frequency and the properties of the fluid being atomized. The effect of the liquid phase viscosity and the flow rate in modifying this correlation has been highlighted by Rajan and Pandit. ${ }^{27}$ There is a good correlation between capillary wavelength and droplet size, and the capillary wavelength increases slowly with liquid phase viscosity. Although Lang's study ${ }^{26}$ is only limited to the low frequency range, many studies ${ }^{28-30}$ have shown that particle size might be directly related to the wavelength of these capillary waves.

Amitriptyline hydrochloride $(\mathrm{AMT} \cdot \mathrm{HCl})$ was chosen as the model drug for this study. This method is an important particle size reduction technology that can be operated both in the laboratory and in industry settings.

\section{Material and methods Materials}

\section{Chemicals}

In general, the model drug (raw $\mathrm{AMT} \cdot \mathrm{HCl}$; purity $=99.6 \%$; $\mathrm{pH}=5.4$ ) was purchased from Hubei Xindali Biochemical Co., Ltd. (Hubei, People's Republic of China). Anhydrous ethanol and diethyl ether of analytical grade were obtained from Chengdu United Chemical Industry Supply and Marketing Storage Limited Company (Chengdu, People's Republic of China). High-purity nitrogen (99.999\%) was bought from Changjun GAS Co, Ltd (Mianyang, People's Republic of China). The ultrasonic nebulizer (402-B) with a series of ultrasonic frequencies was supplied by Jiangsu Yuyue Medical Equipment and Supply Co., Ltd. (Jiangsu, People's Republic of China); the work voltage was $220 \mathrm{~V}$ and the ultrasonic transducer frequency was $1.7 \pm 0.17 \mathrm{MHz}$.

\section{Experimental setup}

The ultrasonic spray-assisted electrostatic experimental installation, which was designed by our own laboratory, is shown in Figure 1. It was made of three main parts: 1) an ultrasonic spray, which is used to generate an aerosol on the upper surface of the liquid of the solution; 2) an oven, which can be heated differently with different zones (the half of the 


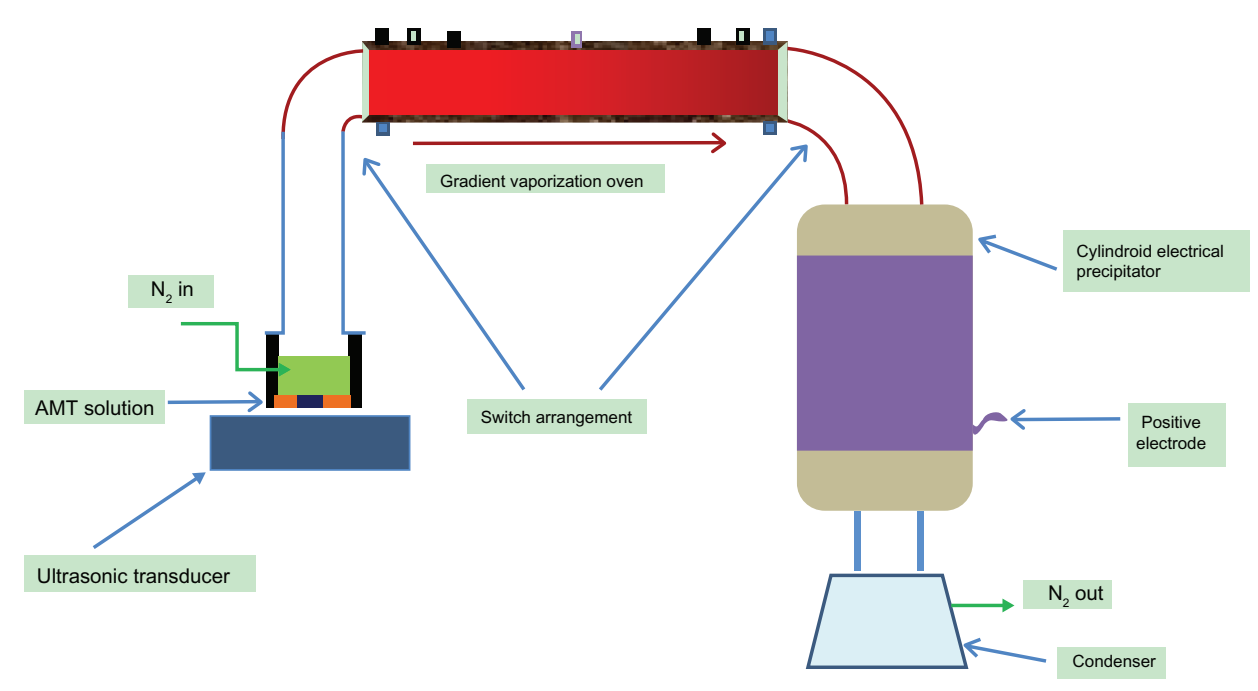

Figure I A brief representation of the crystallization apparatus.

Abbreviation: AMT, amitriptyline.

oven closest to the entry is hot in temperature, and it attenuates this temperature at the other half of the oven); and 3) an electrostatic adsorption precipitator, which is composed of two electrodes, between which an electrostatic field would exist once the switch is turned on. In consideration of safety, and also to balance the efficiency of the installation, the minimum distance of the two electrodes was $9.0 \mathrm{~cm}$.

\section{Methods}

\section{Preparation of AMT $\cdot \mathrm{HCl}$ nanoparticles}

About $0.71 \mathrm{~g}$ of raw $\mathrm{AMT} \cdot \mathrm{HCl}$ was dissolved in $30.0 \mathrm{~mL}$ of anhydrous ethanol (solvent), in a concentration ( $3 \mathrm{wt} \%$ ) below the saturation point at $25^{\circ} \mathrm{C}$. When the ultrasonic spray, which has been given an ultrasonic frequency, is turned on, it produces an aerosol on the upper part of the solution; the aerosol quantity is affected by the frequency, as well as by the liquid level. Then, the aerosol is transported by an inert gas (nitrogen) flow out of the container and turn into droplets.

When the droplet enters the oven, which was heated differently in different zones, the crystallization process of nano-amitriptyline (AMT) is quickly completed upon evaporation of the solvent. The droplet of different size can get a complete crystal growth, as a result of unequal heating. The AMT nanoparticles flow out of the oven with the help of the gas flow, and continue to be dried at a temperature $80^{\circ} \mathrm{C} \pm 1^{\circ} \mathrm{C}$ (which is higher than the boiling point of anhydrous ethanol). As a result of being charged by an electrode (which applied an electrical tension of 3-11 kV), nano-AMT $\cdot \mathrm{HCl}$ was prepared via directional movement from the anode to cathode under the force of electrostatic attraction. The particles produced accumulated close to the bottom of the precipitator. A dry or water-free solvent is very important, because a small amount of water would cause the loss of energy, and cause difficulty in increasing the working temperature. There are few nanoparticles that are stored in the electrostatic adsorption precipitator because most of these particles almost adhere to the inner wall of the oven during the first hour of the experiment. The production rate is constant for a given work parameter, when particles appear in cylindroid electrical precipitator.

\section{Characterization of $\mathrm{AMT} \cdot \mathrm{HCl}$ nanoparticles \\ Scanning electron microscopy}

The morphology and surface appearance of the nanoAMT $\cdot \mathrm{HCl}$ particles were characterized by field scanning electron microscopy (SEM) (Ultra 55; Carl Zeiss Meditec AG, Jena, Germany). The sample was placed on double-sided tape and then observed using field SEM at an acceleration voltage of $15 \mathrm{kV}$ after gold sputtering coating under the vacuum degree of $10^{-6} \mathrm{~Pa}$ for 120 seconds.

\section{Particle size and size distribution}

The average size and particle size distribution of $\mathrm{AMT} \cdot \mathrm{HCl}$ were calculated by means of counting more than 300 particles from the obtained SEM images via the statistics obtained from the SmileView software (JEOL; Tokyo, Japan).

\section{X-ray diffraction}

The phase content of AMT $\cdot \mathrm{HCl}$ was determined by X-ray diffraction (XRD) (X'Pert PRO; PANalytical, Almelo, the Netherlands) analysis using $\mathrm{Cu}-\mathrm{Ka}$ radiation at $50 \mathrm{kV}$ 
and $30 \mathrm{~mA}$, and a monochromatic graphite diffracted beam. The samples were packed into an amorphous silicon holder, and the diffraction angle $(2 \theta)$ was scanned from $5^{\circ} \mathrm{C}-80^{\circ} \mathrm{C}$; the scanning rate was $10^{\circ} \mathrm{C} \cdot$ minute $^{-1}$.

\section{Atomic force microscope}

The imaging of nano AMT $\cdot \mathrm{HCl}$ was carried out in ambient conditions on a SPA300HV atomic force microscope (AFM) (SPA300HV; Japan), which was equipped with a piezoelectric ceramic scanning head. The tapping mode was used with a length of $10 \times 10 \mu \mathrm{m}$ and a spring constant of $40 \mathrm{~N} \cdot \mathrm{m}^{-1}$.

\section{Differential scanning calorimetry}

Samples of raw AMT $\cdot \mathrm{HCl}$ and prepared $\mathrm{AMT} \cdot \mathrm{HCl}$ were analyzed with differential scanning calorimetry (DSC) (Diamond DSC; PerkinElmer, Waltham, MA, USA). The conditions of the DSC were as follows: sample mass: $2.0 \mathrm{mg}$; heating rate: $10 \mathrm{~K} \cdot$ minute $^{-1}$; and nitrogen atmosphere (flow rate: $30 \mathrm{~mL} \cdot$ minute $^{-1}$ ).

\section{Results and discussion Working parameters}

The experimental installation described above runs under the adjustment of several different work parameters, which were all identified with the obtained nanosized medicinal materials and the output of the installation. The droplet size, the main influencing factor (which is decided by the surface tension and the density of the solution that changes with different solvent types), and the excitation frequency offered by ultrasonic transducer have been discussed. The other most important parameters that were identified and studied are discussed in the following sections.

\section{Liquid level in reactor}

The liquid level in the reactor is the first variable involved in the reduction of particle size, as shown in equation 1 , as the droplet can generate via ultrasonic atomization. Conversely, the amount of the droplet that is transported into the system is decided by the liquid level. The level that yields the greatest amount of aerosol can be obtained by a series of experiments.

\section{Solution concentration}

Solution concentration significantly affects the particle size of the product. Generally speaking, there was a positive correlation between the concentration and the average particle size. This means that the high solution concentration yields a large $\mathrm{AMT} \cdot \mathrm{HCl}$ particle size; namely, the particle size decreased with the reduction of the solution's concentration.

\section{Inert gas flow}

Inert gas is used to increase the distance between each droplet and to transport the aerosol and the particle after the nanocrystals form. There is a balance between the transportation and the deposition. Relatively high inert gas flow will result in a loss of the materials, and to the contrary, low inert gas flow will lead to a low production rate or no production.

\section{Working temperatures}

The working temperature of the oven is the key parameter for preparing nanoparticles. In fact, there is a course of crystallization that occurs - the droplet enters into the oven, the liquid evaporates, and the material crystallizes and continues to be dried in the second part of the oven. The temperature of the first part of the oven is about $20^{\circ} \mathrm{C}-40^{\circ} \mathrm{C}$ higher than the boiling point of the solvent (for fast evaporation); otherwise, possible aggregation would occur. In addition, the temperature of the second part of the oven is normally $10^{\circ} \mathrm{C}-20^{\circ} \mathrm{C}$ lower than the first part of the oven in order to reduce the rate of crystallization. This is due to the idea that crystallization that occurs too quickly will make an unexpected deposit in the oven instead of in the precipitator.

\section{Electrical precipitator temperature}

The electrical precipitator is the place where the sample deposits as time goes on; as such, the precipitator should be provided in order for the particle to exist at a temperature that is normally $1^{\circ} \mathrm{C}-3^{\circ} \mathrm{C}$ higher than the boiling point of the solvent.

The results presented below were all obtained with the following working parameters:

- inert gas: $\mathrm{N}_{2}$;

- inert gas flow: $60 \mathrm{~mL} \cdot$ minute $^{-1}$;

- solvent: anhydrous ethanol;

- drug: AMT· $\mathrm{HCl}$;

- ultrasonic transducer frequencies: $1.7 \pm 0.17 \mathrm{MHz}$;

- ultrasonic transducer current/voltage: $200 \mathrm{~mA} / 220 \mathrm{~V}$;

- liquid level in the reactor: $3.0 \pm 0.1 \mathrm{~cm}$; and

- working temperatures: $27^{\circ} \mathrm{C}$ (reactor), $90^{\circ} \mathrm{C}-110^{\circ} \mathrm{C}$ (oven), and $80^{\circ} \mathrm{C} \pm 1^{\circ} \mathrm{C}$ (electrical precipitator).

\section{Characterization of nano- $\mathrm{AMT} \cdot \mathrm{HCl}$ particles}

Nano AMT $\cdot \mathrm{HCl}$ particles were successfully prepared via an ultrasonic spray-assisted electrostatic adsorption method. Figure 2 illustrates the product deposition. 
A

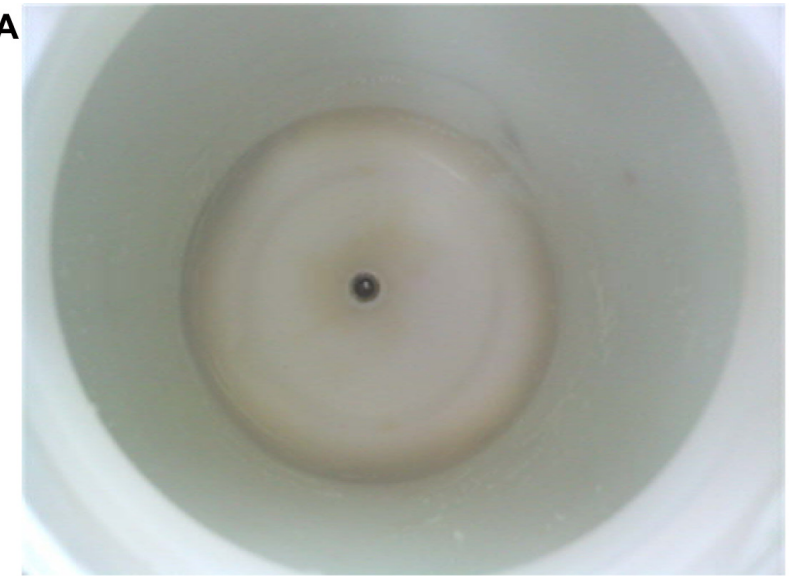

B

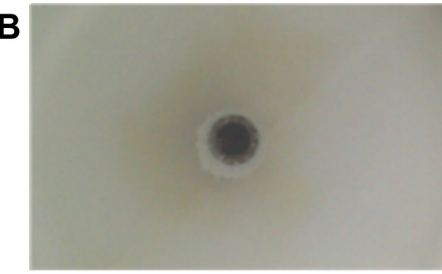

C

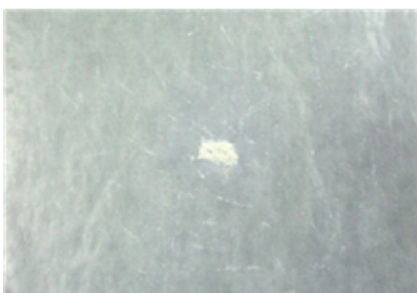

Figure $2 \mathrm{Nano}-\mathrm{AMT} \cdot \mathrm{HCl}$ deposition in the electrical precipitator.

Notes: (A) Nano-AMT · HCl deposition in the electrical precipitator. (B) The center negative electrode. (C) Samples collected from the electrical precipitator. Abbreviation: $\mathrm{AMT} \cdot \mathrm{HCl}$, amitriptyline hydrochloride.

\section{Morphology characterization}

For the SEM analysis, the sample is dispersed in diethyl ether by applying ultrasonic waves of $40 \mathrm{KHz}$ for 30 minutes and vacuum drying for 12 hours. SEM was used to image the morphology of both the raw $\mathrm{AMT} \cdot \mathrm{HCl}$ and prepared $\mathrm{AMT} \cdot \mathrm{HCl}$; the photographs are shown in Figure 3. The image shows a great difference between the raw and prepared samples, which is probably caused by the electrostatic interaction and agglomeration. Raw AMT has a polyhedral morphology and a particle size of about 1-40 $\mu \mathrm{m}$ (Figure $3 \mathrm{~A}$ ), while the prepared AMT size is nearly reduced to $20-300 \mathrm{~nm}$. In addition, there are two groups of nanoAMT $\cdot \mathrm{HCl}$ particles (Figure $3 \mathrm{C}$ ) after ultrasonic processing: a smaller particle size (with an average size of $70 \mathrm{~nm}$ ), and another group with an average particle size of $270 \mathrm{~nm}$. No obvious particle aggregation was observed. The possible reason behind this is that the aerosol size distribution generated by the piezoelectric transducer during the aerosol production process, as well as the chaotic and complex disintegration, is variable. ${ }^{27}$ Thus, small aerosol size droplets crystallize small particles, and at the same time, big aerosol size droplets crystallize big particles during crystallization. In addition, the repulsive force existing in the electrostatic field of each particle reduces the agglomeration between each of the particles. Though the effects of ultrasound can help diminish particle size to a certain extent, the main
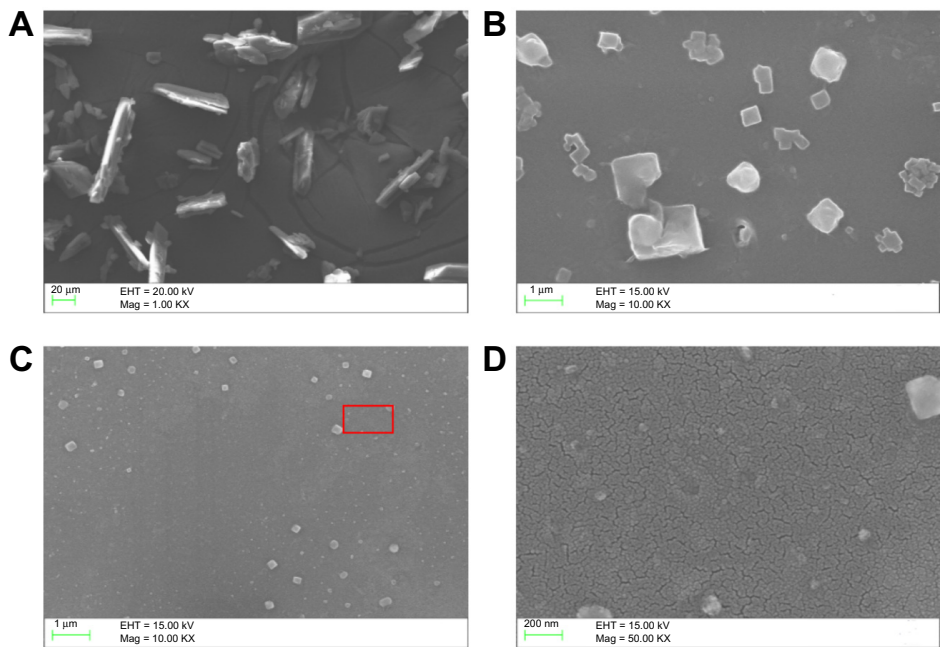

Figure 3 Characterization of raw AMT $\cdot \mathrm{HCl}$ and nano-AMT $\cdot \mathrm{HCl}$.

Notes: Scanning electron microscopic images of $(\mathbf{A})$ raw AMT · HCl; (B) raw AMT · HCl after ultrasonic wave dispersion for 30 minutes; (C) nano-AMT - $\mathrm{HCl}$ after ultrasonic wave dispersion for 30 minutes; and (D) magnification of the red flag area of (C).

Abbreviation: $\mathrm{AMT} \cdot \mathrm{HCl}$, amitriptyline hydrochloride; EHT, extra-high tension; Mag, magnification. 
contribution of being nanosized involves the rupture of the capillary surface waves and their subsequent ejection, in the aerosol process. The suitable particle size distribution of the prepared nanoparticles is also given and the average particle size is about $70 \mathrm{~nm}$ (as shown in Figure 4), and the particle size distribution is relatively narrow with 60-300 nm of smaller sized particles when compared with the distribution of the raw $\mathrm{AMT} \cdot \mathrm{HCl}$ particles (which is determined by counting more than 300 particles from the obtained SEM images).

The sample was prepared by dispersing the nanoparticles in a nonsolvent like diethyl ether, and by applying ultrasonic waves $(40 \mathrm{KHz})$. After complete dispersion, a $3.0 \mathrm{~mL}$ droplet was placed on an atomic flat mica support. The liquid was then evaporated at $60^{\circ} \mathrm{C}$. After the evaporation process, the sample was fixed on the scanning head of the AFM. Figures 5 and 6 show the AFM of a nano-AMT $\cdot \mathrm{HCl}$ sample obtained by using the crystallization process with an ultrasonic transducer frequency of $1.7 \mathrm{MHz}$. The micrograph of Figure 5A provides a global AFM registration of a relatively large scanning area; Figure 5B shows that the threshold of the particles is about $53 \mathrm{~nm}$. The image indicates that the particles have their respective sizes determined by the other techniques.
There are two kinds of particles sizes: elementary particles of about 40-90 $\mathrm{nm}$ in size, and agglomerates of about $100-400 \mathrm{~nm}$ in size (Figure 6A and B). AFM microscopy, which does not need a vacuum or heating, is considered the most suitable method for the characterization of nanoparticle sizes. The sample is not destroyed during the observation, and can therefore be observed.

\section{Physicochemical property characterization}

Another technique that is employed to characterize the obtained product is XRD. XRD was used to determine the phase content, the mean size of the elementary crystallites, and the amorphous degree of the product. The peaks (Figure 7A) of the raw $\mathrm{AMT} \cdot \mathrm{HCl}$ at $2 \theta$ were $18.50^{\circ}, 20.96^{\circ}$, and $22.96^{\circ}$, and the crystalline structure of raw $\mathrm{AMT} \cdot \mathrm{HCl}$ was also observed. The peaks of the prepared AMT $\cdot \mathrm{HCl}$ shift at $2 \theta=20.94^{\circ}$, $22.96^{\circ}$, and $25.80^{\circ}$. Most of the peaks of the nano-AMT $\cdot \mathrm{HCl}$ are presented, indicating that the prepared $\mathrm{AMT} \cdot \mathrm{HCl}$ might be present in a well-crystalline state. As Figure 7B shows, the mean particle size can be calculated by Scherrer's equation. ${ }^{31}$ The obtained result is in the order of $55.0 \mathrm{~nm}$. The results were consistent with the results of the AFM, but were $17 \mathrm{~nm}$ less

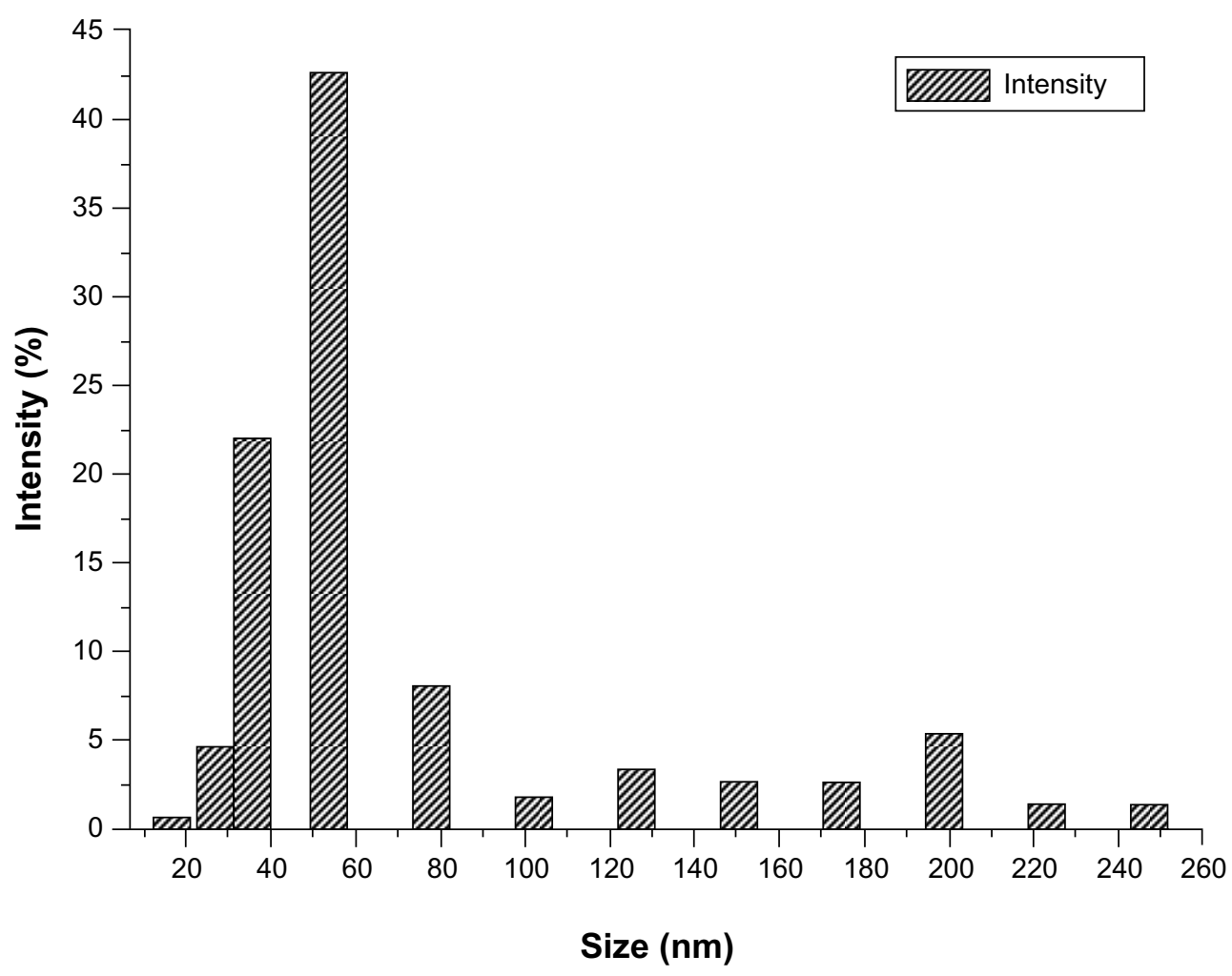

Figure 4 Size distribution of nano-AMT $\cdot \mathrm{HCl}$ particles. Abbreviation: AMT. $\mathrm{HCl}$, amitriptyline hydrochloride. 

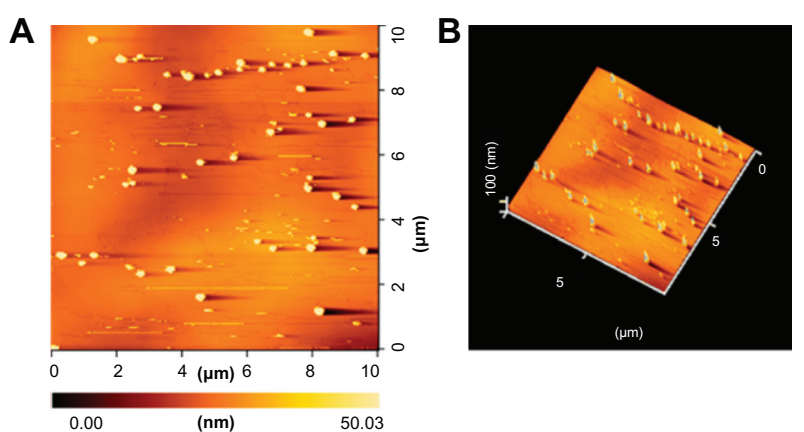

Figure 5 Characterization of nano-AMT. $\mathrm{HCl}$.

Notes: (A) Global AFM-registration of nano-AMT. $\mathrm{HCl}$, and (B) three-dimensional image of nano-AMT. $\mathrm{HCl}$ by dispersing the nanoparticles in a nonsolvent diethyl ether. Abbreviations: $\mathrm{AMT} \cdot \mathrm{HCl}$, amitriptyline hydrochloride; $\mathrm{AFM}$, atomic force microscope.

than with SEM. The possible reason for this is that the applied vacuum and the heating of the sample by the electronic beam induced the instability of the sample. In addition, as the image was taken, time had to be spent to register the whole image, so that the particles formed agglomerates. Figure 8 shows the results of DSC. Raw AMT $\cdot \mathrm{HCl}$ exhibited an obvious melting process, with a peak of $198.2^{\circ} \mathrm{C}$, which implied the crystalline form of AMT $\cdot \mathrm{HCl}$. Furthermore, a tendency of the melting point to decrease was confirmed from $198.2^{\circ} \mathrm{C}$ to $196.3^{\circ} \mathrm{C}$. In order to further explain the experimental results, another sample of a different size was prepared with a different work parameter, and this sample was also tested; the result showed that a similar change was observed by DSC characterization, which agrees well with previously published measurements. ${ }^{32-34}$ The possible reason for the decrease in melting temperature is that more and more atoms are on the surface of the particle, which increases the free surface energy, and consequently decreases the crystal energy by decreasing the particle size. Therefore, precise measuring of the prepared $\mathrm{AMT} \cdot \mathrm{HCl}$ is reasonable and desirable.

\section{Conclusion}

In this work, a new method used to prepare Nano-AMT $\cdot \mathrm{HCl}$ was successfully conducted using the ultrasonic spray-assisted
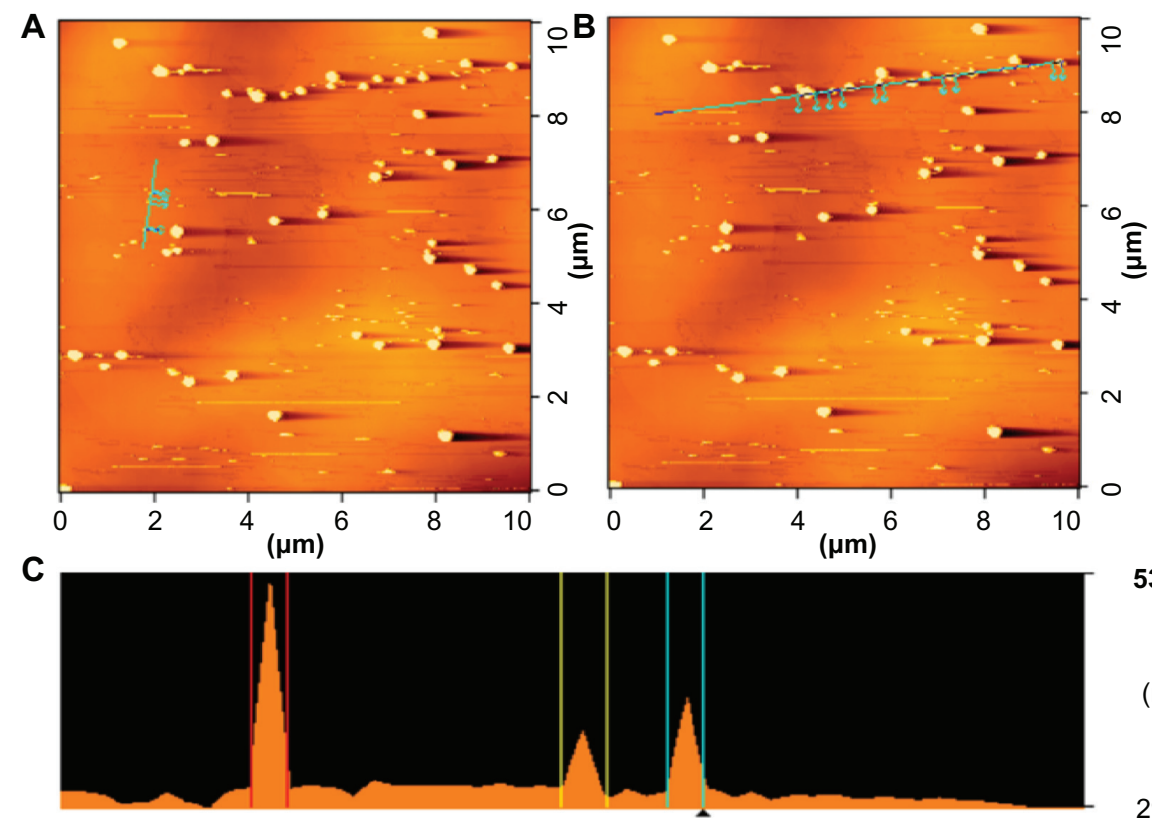

0

$(\mathrm{nm})$

1933.684

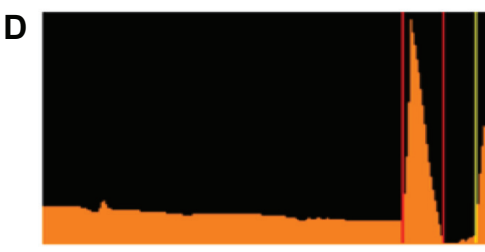

0

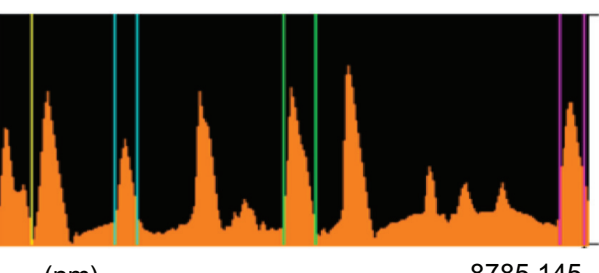

Figure 6 Height measurements on different nano-AMT $\cdot \mathrm{HCl}$ particles.

Notes: Atomic force microscope of (A and C) elementary particles of about 40-90 nm (66 nm, $67 \mathrm{~nm}$, and $86 \mathrm{~nm}$ surfaces analyzed from left to right), and (B and $\mathbf{D})$ agglomerates of about 100-400 nm $(360 \mathrm{~nm}, 291 \mathrm{~nm}, 188 \mathrm{~nm}, 274 \mathrm{~nm}$, and $205 \mathrm{~nm}$ surfaces analyzed from left to right).

Abbreviation: $\mathrm{AMT} \cdot \mathrm{HCl}$, amitriptyline hydrochloride. 


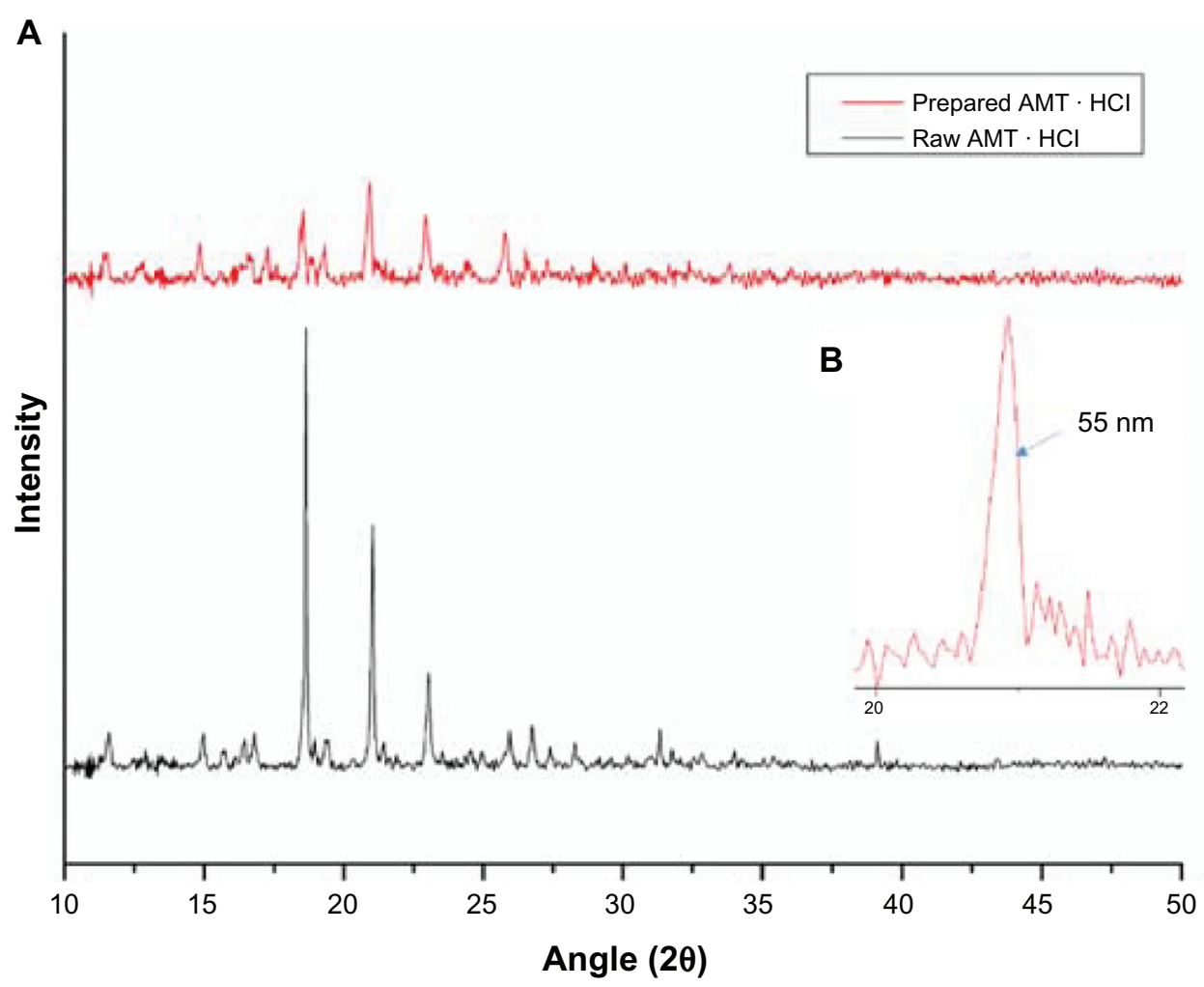

Figure 7 XRD of raw AMT $\cdot \mathrm{HCl}$ and prepared $\mathrm{AMT} \cdot \mathrm{HCl}$.

Notes: (A) Patterns of AMT $\cdot \mathrm{HCl}$. (B) Mean size determination of the nanoparticles by XRD.

Abbreviations: $\mathrm{AMT} \cdot \mathrm{HCl}$, amitriptyline hydrochloride; $\mathrm{XRD}, \mathrm{X}$-ray diffraction.

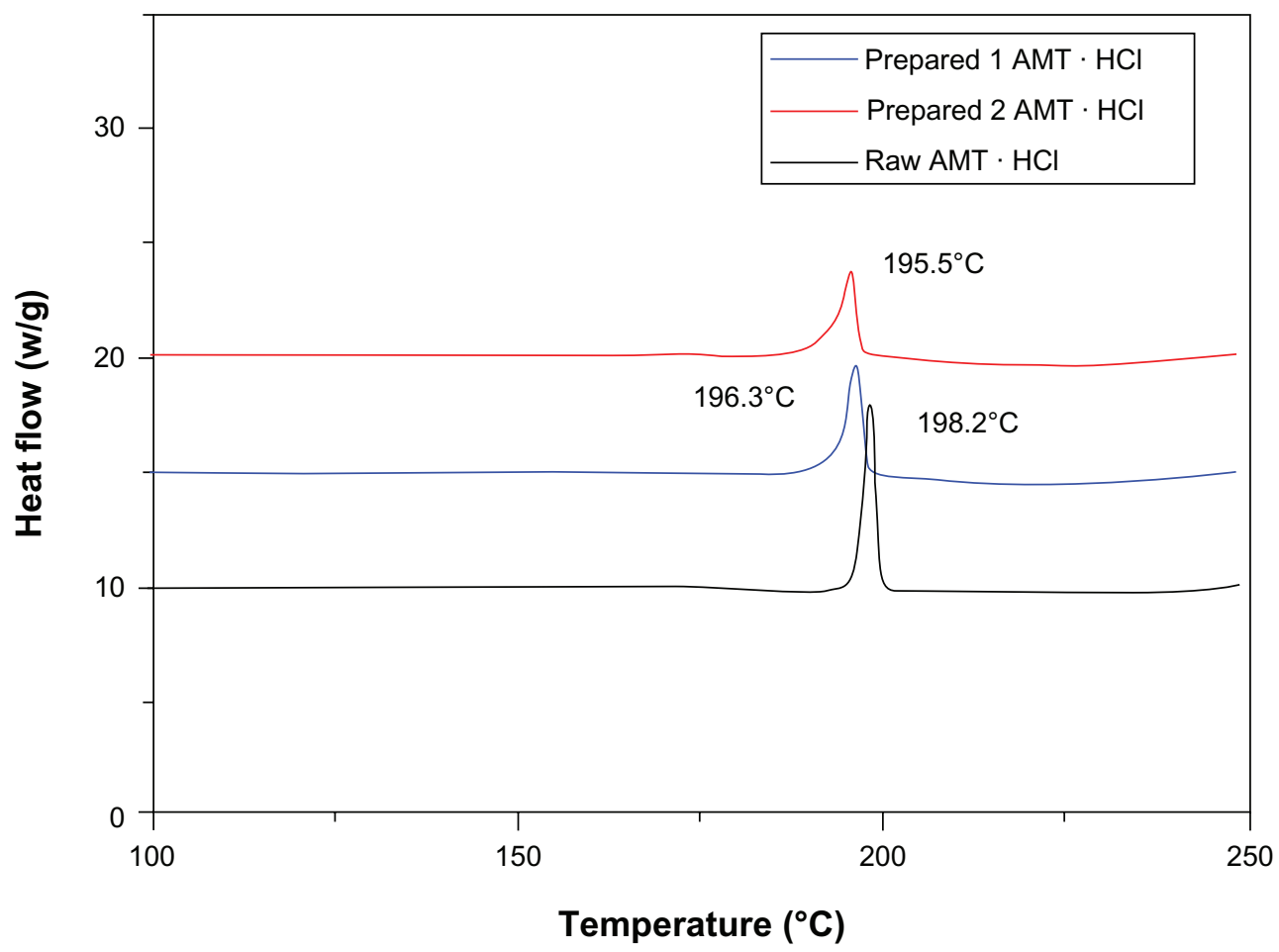

Figure $8 \mathrm{DSC}$ curves for raw $\mathrm{AMT} \cdot \mathrm{HCl}$ and prepared $\mathrm{AMT} \cdot \mathrm{HCl}$.

Notes: Sample I and sample 2; heating rate: $10^{\circ} \mathrm{C}$ minute $^{-1}$. The particle size of sample 2 is about $60 \mathrm{~nm}$ (not displayed here).

Abbreviations: AMT $\cdot \mathrm{HCl}$, amitriptyline hydrochloride; DSC, differential scanning calorimetry. 
electrostatic adsorption method. The mean particle size of nano-AMT is $53 \mathrm{~nm}$, and it presents with a narrow particle size distribution. This method can be used for other drug materials, such as doxorubicin and so on, but differences exist in terms of the solvent, temperature, and other working parameters. Different characterization methods showed that the nanosized drug crystals can be produced continuously via this method. Ultrasonic spray-assisted electrostatic adsorption is a very effective and continuous method to produce drug nanocrystals. This method is also applied to poorly water-soluble drugs, and it is a very effective alternative for industrial production.

\section{Acknowledgments}

This work was supported by the National Natural Science Foundation of China (Project number 11002128, 11272292, and 11172276), and by the Analytical and Testing Center, Southwest University of Science and Technology.

\section{Disclosure}

The authors report no conflicts of interest in this work.

\section{References}

1. Psimadas D, Georgoulias P, Valotassiou V, Loudos G. Molecular nanomedicine towards cancer: ${ }^{111}$ In-labeled nanoparticles. J Pharm Sci. 2012;101(7):2271-2280.

2. Sumer B, Gao J. Theranostic nanomedicine for cancer. Nanomedicine (Lond). 2008;3(2):137-140.

3. Thierry B, Textor M. Nanomedicine in focus: opportunities and challenges ahead. Biointerphases. 2012;7(1-4):19.

4. Gilert A, Machluf M. Nano to micro delivery systems: targeting angiogenesis in brain tumors. J Angiogenes Res. 2010;2:20.

5. Law WC, Mahajan SD, Kopwitthaya A, et al. Gene silencing of human neuronal cells for drug addiction therapy using anisotropic nanocrystals. Theranostics. 2012;2(7):695-704.

6. Damgé C, Maincent P, Ubrich N. Oral delivery of insulin associated to polymeric nanoparticles in diabetic rats. $J$ Control Release. 2007;117(2):163-170.

7. Sivasankar M, Kumar BP. Role of nanoparticles in drug delivery system. International Journal of Research in Pharmaceutical and Biomedical Sciences. 2010;1(2):41-66.

8. Rekhi GS. Advances in solid dose oral drug delivery. ON Drug Delivery: Oral Drug Delivery and Advanced Excipients. 2010:14-18.

9. Xia Y. Nanomaterials at work in biomedical research. Nat Mater. 2008;7(10):758-760.

10. Schrade A, Cao Z, Landfester K, Ziener U. Preparation of raspberrylike nanocapsules by the combination of Pickering emulsification and solvent displacement technique. Langmuir. 2011;27(11):6689-6700.

11. Chen Y, Chen H, Zeng D, et al. Core/shell structured hollow mesoporous nanocapsules: a potential platform for simultaneous cell imaging and anticancer drug delivery. ACS Nano. 2010;4(10):6001-6013.

12. Wang Y, Li X, Zhou Y, Huang P, Xu Y. Preparation of nanobubbles for ultrasound imaging and intracelluar drug delivery. Int $J$ Pharm. 2010;384(1-2):148-153.

13. Yang S, Qian X, Xu Y, Tao X, Zhao C. In vitro evaluation of $\mathrm{pH}$-sensitive doxorubicin nanoliposomes modified with carboxymethyl chitosan. Proceedings of the Shanghai International Nanotechnology Cooperation Symposium, 30 Oct-Nov 1 2011. Shanghai, People's Republic of China; 2011;46-50.
14. Samadikhah HR, Majidi A, Nikkhah M, Hosseinkhani S. Preparation, characterization, and efficient transfection of cationic liposomes and nanomagnetic cationic liposomes. Int J Nanomedicine. 2011;6(6):2275-2283.

15. Cheng R, Feng F, Meng F, Deng C, Feijen J, Zhong Z. Glutathioneresponsive nano-vehicles as a promising platform for targeted intracellular drug and gene delivery. $J$ Control Release. 2011;152(1):2-12.

16. Daum N, Tscheka C, Neumeyer A, Schneider M. Novel approaches for drug delivery systems in nanomedicine: effects of particle design and shape. Wiley Interdiscip Rev Nanomed Nanobiotechnol. 2012;4(1):52-65.

17. Sherlock SP, Tabakman SM, Xie L, Dai H. Photothermally enhanced drug delivery by ultrasmall multifunctional $\mathrm{FeCo} /$ graphitic shell nanocrystals. ACS Nano. 2011;5(2):1505-1512.

18. Merisko-Liversidge E, Liversidge GG, Cooper ER. Nanosizing: a formulation approach for poorly-water-soluble compounds. Eur J Pharm Sci. 2003;18(2):113-120.

19. Rotello VM. Nanoparticles: building blocks for nanotechnology. 1st ed. New York, NY: Springer-Verlag; 2004.

20. Junghanns JUAH, Müller RH. Nanocrystal technology, drug delivery and clinical applications. Int J Nanomedicine. 2008;3(3):295-310.

21. Salah N, Habib SS, Khan ZH, et al. High-energy ball milling technique for $\mathrm{ZnO}$ nanoparticles as antibacterial material. Int $J$ Nanomedicine. 2011;6:863-869.

22. Biazar E, Beitollahi A, Rezayat SM, et al. Effect of the mechanical activation on size reduction of crystalline acetaminophen drug particles. Int J Nanomedicine. 2009;4:283-287.

23. Shah N, Iyer RM, Mair HJ, et al. Improved human bioavailability of vemurafenib, a practically insoluble drug, using an amorphous polymer-stabilized solid dispersion prepared by a solvent-controlled coprecipitation process. J Pharm Sci. 2013;102(3):967-981.

24. Kole PL, Venkatesh G, Kotecha J, Sheshala R. Recent advances in sample preparation techniques for effective bioanalytical methods. Biomed Chromatogr. 2011;25(1-2):199-217.

25. Muller RH, Becker R, Kruss B, Peters K, inventors. Pharmaceutical nanosuspensions for medicament administration as systems with increased saturation solubility and rate of solution. Jan 12,1999. United States patent US 5858410.

26. Lang RJ. Ultrasonic atomization of liquids. J Acoust Soc Am. 1962; 34(1):6-8.

27. Rajan R, Pandit A. Correlations to predict droplet size in ultrasonic atomisation. Ultrasonics. 2001;39(4):235-255.

28. McCubbin TK Jr. The particle size distribution in fog produced by ultrasonic radiation. J Acoust Soc Am. 1953;25(5):1013-1014.

29. Rajagopal ES. Particle size distributions in ultrasonic emulsification. Proceedings of the Indican Academy of Sciences - Section A. 1959;49(6):333-339.

30. Avvaru B, Patil MN, Gogate PR, Pandit AB. Ultrasonic atomization: effect of liquid phase properties. Ultrasonics. 2006;44(2):146-158.

31. Zhu X, Birringer R, Herr U, et al. X-ray diffraction studies of the structure of nanometer-sized crystalline materials. Phys Rev B. 1987; 35(17):9085-9090.

32. Chen J, Sun Q, Zou Y, Xue G. DSC studies on the melting crystallization of polyethylenes prepared from alkanes of varying molecular size. Polymer. 2002;43(25):6887-6891.

33. Liu H, Armand JY, Bouzon J, Vergnaud JM. Effect of sample size and heating rate on the DSC process for reactions of high enthalpy. Thermochim Acta. 1988;126(15):81-92.

34. Armand JY, Gonnet R, Jones R, Bouzon J, Touchard M, Vergnaud JM. Effect of heating rate and sample size on heat transfer through the sample in DSC. Thermochim Acta. 1986;103(2): 341-351. 


\section{Publish your work in this journal}

The International Journal of Nanomedicine is an international, peerreviewed journal focusing on the application of nanotechnology in diagnostics, therapeutics, and drug delivery systems throughout the biomedical field. This journal is indexed on PubMed Central, MedLine, CAS, SciSearch $\AA$, Current Contents ${ }^{\circledR} /$ Clinical Medicine,
Journal Citation Reports/Science Edition, EMBase, Scopus and the Elsevier Bibliographic databases. The manuscript management system is completely online and includes a very quick and fair peer-review system, which is all easy to use. Visit http://www.dovepress.com/ testimonials.php to read real quotes from published authors.

Submit your manuscript here: http://www.dovepress.com/international-journal-of-nanomedicine-journal 